\title{
DISCUSSION
}

\section{“NEW ZEALAND NATIONAL SOCIETY FOR EARTHQUAKE ENGINEERING DISCUSSION GROUP ON THE SEISMIC DESIGN OF BRIDGES"}

\author{
BULLETIN VOL. 13, NO. 3, SEPTEMBER, 1980
}

\section{Discussion by John E. Rinne*}

Bridge failures in earthquakes, like failures of buildings supposedly designed with adequate earthquake resistance, have become an embarrassment to the engineering profession. We seem to have failed to have learned from our failures. A highly respected professor of the writer, many years ago, stated to the effect: "If your analysis does not accord with your observation of performance, look to errors in the analysis, not in the performance". This seems to apply so aptly to the case of the performance of bridges in earthquakes. The most recent one, in Humboldt County, California, displayed the too often experienced dropping off the supports.

A recent paper on "Structural Failures and the Growth of Engineering Knowledge" by D.I. Blockley and J.R. Henderson ${ }^{1}$ published in the Proceedings of the Institution of Civil Engineers has particular relevance to this subject. It points up both the parallels and significant differences in the development of scientific knowledge and engineering knowledge. Included with the scientists are structural analysts. Science, mathematics and analysis are important parts of engineering, but are only a part. The objective of engineering is to design and build structures to perform. This requires, in addition to analysis, the application of judgment based on experience and observation, empirical rules which have been tested and produce desired results. and the application of cautious, "safe" theories. The scientist (analyst) on the other hand, is willing to make simplifying assumptions to support the calculation procedure model. This has a direct bearing on the bridge problem.

Structural analysts have become so enamored with the electronic computer and its application to dynamics, elastically and elasto-plastically, as used in earthquake analyses, that some of the basic assumptions of input may be grossly inaccurate. This is not to criticize the computer; it is a great tool. However, the representation of the ground motion unidirectionally - as time-history or spectral response - is about as far from the truth as one can get. Yet this is what seems to be advocated here and in New Zealand.

It appears that bridges - for the convenience of the analyst - are to be

*Past President IAEE, Kensington, California, U.S.A. treated much like buildings. There are some important differences between buildings and bridges that are quite obvious but not recognized in the design criteria. Building foundations are tied together, usually by a ground level floor slab. This rationalizes the building responding to ground motions as a unit, at least the horizontial. components of the grourd motion. Bridges, on the other hand, are characterized by having two or more independent supports. What is important is that the ground motion experienced by these supports is a complex of translational and rotational motions out of phase on one support versus another support.

The rotational motion at the bottom of the pier support multiplied by the height of the pier gives a lateral motion at the deck level very considerably magnified. Forces far exceed those that can be resisted by restraining bolts shown in some of the N.Z. details.

Longitudinally, with simple supports on typically narrow support shelf, the motions of the tops of piers have been enough to cause the span to drop. This has been the experience frequently in earthquakes. The solution is to provide continuity over supports, even including the abutment supports. Transversely, the pier and deck are usually able to accommodate the motions, but designs should recognize lateral motions considerably in excess of those predicted by analysis alone.

Potential slope instability at the abutments during earthquake make it preferable not to aggravate this by superimposing a substantial vertical load reaction at the top of the slope. Depending upon the geometry of the profile, it might be better to cantilever a portion of the deck off a supporting pier which is at or near the bottom of the slope, to bring little or no load to the abutment structure.

\section{REFERENCE:}

(1) Structural Failures and the Growth of Engineering Knowledge by D.I. Blockley and J.R. Henderson. Proceedings of the Institution of Civil Engineers, Part I, November 1980 Vol. 68 


\section{REPLY BY NZNSEE BRIDGE DISCUSSION GROUP:}

The members of the bridge design group thank Mr Rinne for his interest and comments. The following observations are made concerning some of the points Mr Rinne raised.

The group adknowledges that it is of importance for all major bridges that a sound concept be developed so that the total performance of the bridge and its site can be predicted with a high degree of reliability. The NZNSEE papers give due recognition to this aspect in section I entitled "Design Philosophy". Clause 1.4 describes the Design Process. The three basic skills comprising concept, analysis and detailing are discussed to put into perspective the features necessary for a sound design.

The ability to conceive the best structural form is something which can only be gained through extensive experience of many types of structure. The skill to estimate the response of a particular structure and the interaction between the soil and the structure by analysis requires considerable theoretical knowledge. The point is made that choice of a simple structural form is to be preferred, since the performance of such a structure can be more reliably predicted. Careful detailing is required to ensure that all parts of the bridge behave reliably, and in accordance with the designer's intentions.

It is appreciated that the recommendations are somewhat more complicated than those in general use at present and that this may give rise to the criticism that they are excessively theoretical. The reason for the complexity is to enable the designer to provide appropriate strength and ductility at minimum cost. Simpler recommendations may well be possible but they would tend to be less economic. The complexity in the recommendations is seen as justified in New Zealand where major bridges are designed by specialists and any complexity in the recommendations is not seen as presenting them any problems. With advancing research and further site experience it is expected it will be possible to make simplifications but the present recommendations represent a summary of the state of the art in New Zealand.

Structural failures, from whatever cause, are generally an embarrassment to the engineering profession. However, bridge failures recorded have occurred in structures designed by methods significantly different from those currently used and recommended in the papers. In times when design methods are changing rapidly, even recently-built structures designed to earlier codes can contain shortcomings relative to current design practice. Much effort has been spent in recent years on improving design methods for, and understanding of, seismic behaviour of bridges. Before 1970 bridge design practice did not relate to the dynamic and extreme nature of possible earthquake shaking. Poor liaison between bridge designers on the one hand, and building designers and university researchers on the other, created a major barrier in various countries to improved design methods. Interdisciplinary exchanges of personnel in New Zealand have been beneficial, as has been the increased amount of bridge-related research. In California the San Fernando earthquake bridge collapses gave the incentive for more bridge research. Much has already emerged from the subsequent efforts. Further benefits will no doubt result from the programmes recommended in Reference 1. Thus it is believed that few bridges designed to the recently developed codes and principles have yet been tested by a severe real-life shaking and the moment of truth has yet to arrive.

Mr Rinne's comments concerning assumed unindirectional loading relative motion of pier bases, the refinement of analysis and the crudeness of assumed input motions would, it is believed, generally be recognised by experienced seismic engineers. The NZNSEE papers contain reference to this aspect in Clauses C2.1.4., C3.4.2. paragraph 2, Clo general comment and C10.3. It is for this reason that New Zealand practice emphasises the importance of creating a well detailed structure with a generous forgiving nature in the form of ample ductile capacity in excess of that theoretically required, and in contrast to a structure of 'short tempered' and brittle nature. The emphasis on the capacity design approach in section 3 is aimed at this objective, as is the requirement for linkage bolts at all movement joints between spans. Minimum seating lengths proposed are substantially in excess of those which have resulted in spans falling in recent earthquakes. (Refer Clause 8.2 and figures 8.1 and 8.2 ).

Reference to forces in restraining bolts between spans far exceeding those that can be resisted by bolts shown in some New Zealand details would be true if one considered only elastic response and consequent forces. Experience has shown that it is impractical to design for elastic behaviour, even in linkage bolts (the strength of practically sized concrete diaphragms becomes a limiting factor in longer spans). A philosophy of assuming the linkage bolts can yield without rupture is therefore adopted (see detail figure 8.3 of the papers, with linkage bolt machined down to guard against thread failure. An alternative is to use a rolled-on thread). Protection against transverse shearing of linkage bolts is of course important.

In practice, the adopted solution to a bridging problem will depend on constraints such as serviceability under traffic loading, method of erection and, not least, cost. While it is essential for the designer to be aware of good seismic design principles such as using continuous structures over supports, such options are not always economically practical. 
In the small to medium sized range of bridging, simple span 'standard beam' construction has been proven to be by far the most economical. In long structures temperature effects usually demand structural breaks, and these cannot often be provided at midspan, with cantilevers over adjacent piers. Thus, solutions such as the deck linkage slab or linkage bolts (see figure 8.2 of the papers) become an attractive proposition. It is certainly important that the basic structural form is chosen with due consideration being given to seismic behaviour, and this is summed up in section 1.4.1 of the bridge papers. Such aspects are unfortunately not the only ones governing a design.

REFERENCE:

(1) "Proceedings of a Workshop on Earthquake Resistance of Highway Bridges" sponsored by US National Science Foundation and conducted by the Applied Technology Council, January 1979. 